\title{
Switching frequency control method based on short prediction horizon control algorithm of Quasi-Z source inverter
}

\author{
Shengchao $\mathrm{Li}^{1}$, Sile $\mathrm{Ma}^{* 2}$, Xiaojing $\mathrm{Ma}^{2}$, Xiangyuan Jiang ${ }^{2}$, Shuai $\mathrm{Li}^{3}$ \\ ${ }^{1}$ College of Marine Scinec and Technology, Northwestern Polytechnical University, Xi'an, China \\ ${ }^{2}$ The Institute of Marine Science and Technolgoy (IMST), Department of Control Science and Engineering, Shandong University, \\ Qingdao, China \\ ${ }^{3}$ Department of Computing, The Hong Kong Polytechnic University, Hung Hom, Kowloon, Hong Kong, China
}

Received: October 23, 2018

Accepted: November 20, 2018 Online Published: December 7, 2018

DOI: $10.5430 /$ ijrc.v2n1p1

URL: https://doi.org/10.5430/ijrc.v2n1p1

\begin{abstract}
In order to overcome the problem of large inductance current ripple and poor output current quality caused by lower switching frequency in model predictive control (MPC). A short prediction horizon control algorithm is proposed, and the relationship between the prediction horizon and the switching frequency is analyzed, which also considered the influence of the switching frequency of the inverter. In the proposed algorithm the optimal vector is selected based on the historical switching state. Finally the proposed method can effectively reduce the inductor current ripple and improve the output current quality of the inverter, which is proved by simulation and experiment.
\end{abstract}

Key Words: MPC, Switching frequency, Prediction horizon

\section{INTRODUCTION}

Compared with the traditional inverter, the quasi-Z source inverter ${ }^{[1]}$ introduces a shoot-through boost mechanism, which has excellent performances such as high reliability, flexible buck-boost and high anti-interference. Because of those advantages, the quasi- $Z$ source inverter has been widely used in photovoltaic power generation, ${ }^{[2,3]}$ wind power and other distributed power generation systems. ${ }^{[4]}$ The DC side of the quasi-Z source inverter uses a shoot-through mechanism to boost the DC input $V$ in, and inverts the DC to AC to provide energy for the load. Therefore, the DC side and the AC side need to be controlled at the same time. The traditional PI control method have a good control effect on the system, but a separate controller needs to be designed, and in order to be able to control the multiple variables simultaneously, which requires multiple control loops, which will increase the complexity of the system design.

MPC has been rapidly developed since the 1970 s. $^{[5,6]}$ Compared with PI and other control methods, MPC can control multiple variables at the same time, and which has the advantages of simple structure and good control effect, ${ }^{[7-9]}$ especially for the non-minimum phase systems such as MIMO systems and quasi-Z-source inverters. ${ }^{[10-12]}$ The MPC uses the current feedback value to predict the next switching state, and the switching of the switching tube is determined by

\footnotetext{
* Correspondence: Sile Ma; Email: masile@sdu.edu.cn; Address: The Institute of Marine Science and Technolgoy (IMST), Department of Control Science and Engineering, Shandong University, Qingdao, China. 
the predicted value. Therefore, MPC belongs to variable frequency control. Mostafa Mosa et al. ${ }^{[13,14]}$ used the MPC algorithm to regulate the inductor current, capacitor voltage and load current of the quasi-Z-source inverter, although which achieved a good tracking effect, the prediction horizon is a little longer, which may cause the inductor current ripple to be relatively large, and the inverter's output characteristics are relatively poor. Abualkasim Bakeer et al. ${ }^{[15]}$ analyzed the state equations of the inductor current, then divided the inductor current into two states, that is the shoot-through state and the non-shoot-through state, which reduced the calculation of the MPC. The real-time performance of MPC is greatly improved, but the inverter still has a low switching frequency phenomenon. Ayman Ayad et al. ${ }^{[16]}$ added two capacitors and two inductors into the predictive model, which improved the accuracy of the predictive model, and the average switching frequency is added to the cost function to reduce the switching loss. However, the impact on the switching frequency is too high and the problem caused by the low switching frequency is still not solved.

Therefore, based on the literatures by Mosa M et al., ${ }^{[13,14]}$ a short prediction horizon control algorithm is proposed. Firstly, this paper analyzed the relationship between the prediction horizon and the switching frequency of the inverter. Then, established the state space model of inductor current, capacitor voltage and load current ${ }^{[15]}$ to improve the accuracy of the prediction model. Finally, the simulation and experiment result certify that the proposed methods can improves the output characteristics of the inverter, and which has some practical values.

\section{MAThematical MOdel}

The quasi-Z source inverter consists of quasi-Z source impedance network, three-phase inverter bridge and $R L$ load. The quasi- $Z$ source impedance network includes two identical inductors $L_{1}$ and $L_{2}$, two identical capacitors $C_{1}$ and $C_{2}$, and a diode. Quasi-Z-source inverter topology shown in Figure 1.

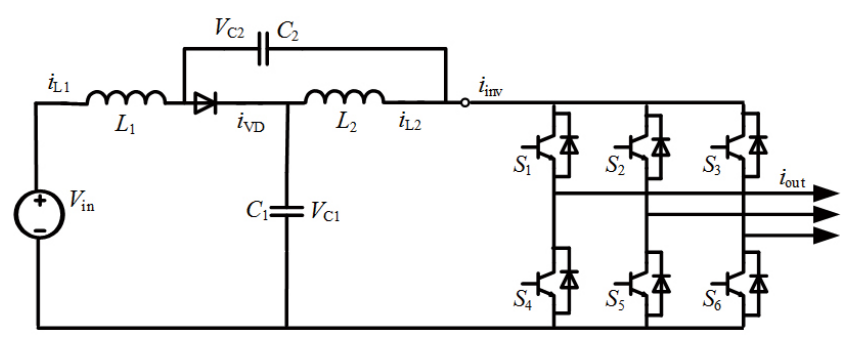

Figure 1. Topology of Quasi-Z source inverter

The state of the MPC system is: $x=\left[\begin{array}{llllll}i_{\alpha} & i_{\beta} & i_{L 1} & i_{L 2} & V_{C 1} & V_{C 2}\end{array}\right]^{T}$

The output of the MPC system is:

$y=\left[\begin{array}{llll}i_{\alpha} & i_{\beta} & i_{L 1} & V_{C 1}\end{array}\right]^{T}$

\subsection{Non-shoot-through state}

The non-shoot-through includes an active vector and a zero vector. When the inverter is working on non-shoot-through state the diode is turned on, during that time the input DC source and inductor provide energy to the load. The circuit of the quasi-Z source inverter is shown in Figure 2.

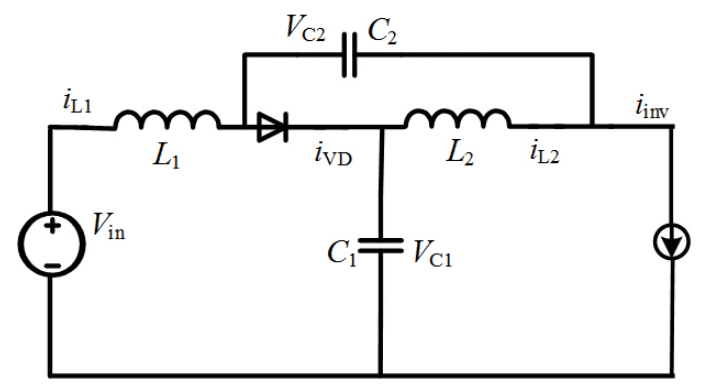

Figure 2. Non-shoot-through state

According to the dynamic transformations of load current, capacitor voltage and inductor current, the state space model of the non-shoot-through state is:

$$
\begin{aligned}
& \frac{d x(t)}{\mathrm{d} t}=A_{1} x(t)+B_{1} u_{a b c}(t) \\
& y(t)=C x(t)
\end{aligned}
$$

Where: $u_{a b c}$ is three-phase voltage of the inverter

$$
A_{1}=\left[\begin{array}{cccccc}
-\frac{R}{L} & 0 & 0 & 0 & 0 & 0 \\
0 & -\frac{R}{L} & 0 & 0 & 0 & 0 \\
0 & 0 & 0 & 0 & -\frac{1}{L_{1}} & 0 \\
0 & 0 & 0 & 0 & 0 & -\frac{1}{L_{2}} \\
-\frac{u_{a b c}^{T} K_{(; 1)}^{-1}}{C_{1} R} & -\frac{u_{a b c}^{T} K_{(;, 2)}^{-1}}{C_{1} R} & \frac{1}{C_{1}} & 0 & 0 & 0 \\
-\frac{u_{a b c}^{T} K_{(; ; 1)}^{-1}}{C_{2} R} & -\frac{u_{a b c}^{T} K_{(;, 2)}^{-1}}{C_{2} R} & 0 & \frac{1}{C_{2}} & 0 & 0
\end{array}\right]
$$




$$
B_{1}=V_{d c l i n k}\left[\begin{array}{cc}
\frac{1}{L} & 0 \\
0 & \frac{1}{L} \\
0 & 0 \\
0 & 0 \\
0 & 0 \\
0 & 0
\end{array}\right] K \quad C=\left[\begin{array}{llllll}
1 & 0 & 0 & 0 & 0 & 0 \\
0 & 1 & 0 & 0 & 0 & 0 \\
0 & 0 & 1 & 0 & 0 & 0 \\
0 & 0 & 0 & 0 & 1 & 0
\end{array}\right] K=\frac{2}{3}\left[\begin{array}{ccc}
1 & -\frac{1}{2} & -\frac{1}{2} \\
0 & \frac{\sqrt{3}}{2} & -\frac{\sqrt{3}}{2}
\end{array}\right]
$$

\subsection{Shoot-through state}

When the inverter is working on shoot-through state, the upper and lower tubes would simultaneously turned on at least one phase, and the load is short-circuited, and the diode is in the off state, so that the input DC source and the capacitor are charged for the inductor, and the quasi- $\mathrm{Z}$ source inverter equivalent circuit is shown in Figure 3.

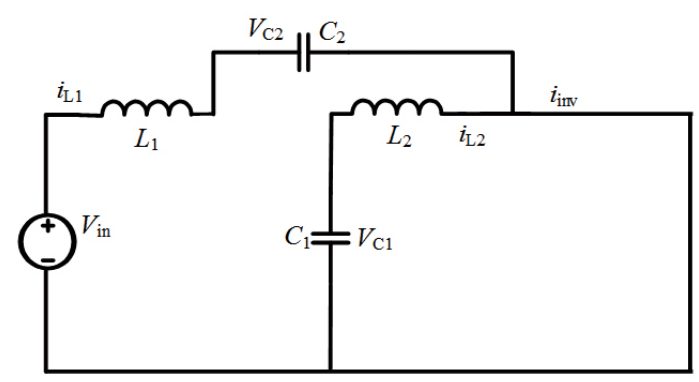

Figure 3. Shoot-through state

According to the dynamic transformations of load current, capacitor voltage and inductor current, the state space model of the shoot-through state is:

$$
\begin{aligned}
& \frac{d x(t)}{\mathrm{d} t}=A_{2} x(t)+B_{2} u_{a b c}(t) \\
& y(t)=C x(t)
\end{aligned}
$$

Where:

$$
A_{2}=\left[\begin{array}{cccccc}
-\frac{R}{L} & 0 & 0 & 0 & 0 & 0 \\
0 & -\frac{R}{L} & 0 & 0 & 0 & 0 \\
0 & 0 & 0 & 0 & 0 & \frac{1}{L_{1}} \\
0 & 0 & 0 & 0 & \frac{1}{L_{2}} & 0 \\
0 & 0 & 0 & -\frac{1}{C_{1}} & 0 & 0 \\
0 & 0 & -\frac{1}{C_{2}} & 0 & 0 & 0
\end{array}\right]
$$

$B_{2}$ is a zero matrix of the same dimension as $B_{1}$.

Comparing the state space expressions of the shoot-through state and the non-shoot-through state, we can find that a shoot-through variable $d$ can be introduced to simplify the state space model.

$$
\frac{d x(t)}{\mathrm{d} t}=A x(t)+B u_{a b c}(t)
$$

$$
y(t)=C x(t)
$$

Where:

$$
\begin{aligned}
& A=\left[\begin{array}{cccccc}
-\frac{R}{L} & 0 & 0 & 0 & 0 & 0 \\
0 & -\frac{R}{L} & 0 & 0 & 0 & 0 \\
0 & 0 & 0 & 0 & \frac{d-1}{L_{1}} & \frac{d}{L_{1}} \\
0 & 0 & 0 & 0 & \frac{d}{L_{2}} & \frac{d-1}{L_{2}} \\
\frac{m_{1}}{C_{1}} & \frac{m_{2}}{C_{1}} & \frac{1-d}{C_{1}} & -\frac{d}{C_{1}} & 0 & 0 \\
\frac{m_{1}}{C_{2}} & \frac{m_{2}}{C_{2}} & -\frac{d}{C_{2}} & \frac{1-d}{C_{2}} & 0 & 0
\end{array}\right] \\
& m_{1}=\frac{(d-1) u_{a b c}^{T} K^{-1}}{R}, \quad m_{2}=\frac{(d-1) u_{a b c}^{T} K^{-1}}{R}, \quad B=(1-d) B_{1}, \quad d= \begin{cases}0 \quad \text { Non-shoot-through } \\
1 \quad \text { shoot-through }\end{cases}
\end{aligned}
$$

\subsection{MPC model}

The MPC model is obtained by using the Euler forward difference formula to align the state space expression into discrete state of the quasi-Z source inverter.

$$
\begin{aligned}
& x(k+1)=G x(k)+H u_{a b c}(k) \\
& y(k)=C x(k)
\end{aligned}
$$

Where $u_{a b c}$ is the three-phase output voltage of the inverter, $G=A T_{s}+I, H=B T_{s}, I$ is the unit matrix, and $T_{s}$ is the prediction horizon.

In order to obtain the optimal switching action, firstly, the predictive control model is used to predict the state of inductor current, capacitor voltage and load current. Secondly, the deviation between the state of $k+1$ and the reference instruction is compared, and then combine the weight coefficient to obtain the optimal state vector at time $k+1$. Finally, the optimal switching action is selected in combination with the switching frequency, and driven the inverter to adjust the controlled variable. The control block diagram of the predictive control algorithm is shown in Figure 4. 


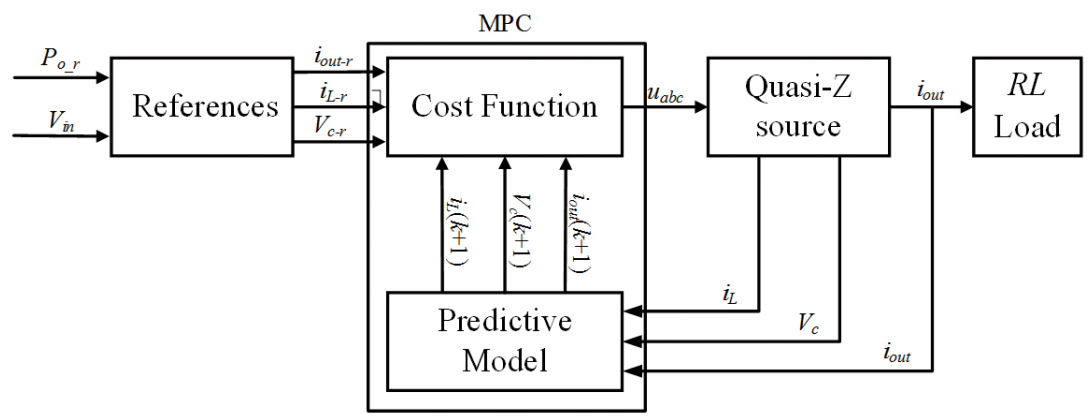

Figure 4. Shoot-through state

\section{INDUCTOR CURRENT RIPPLE ANALYSIS}

Predictive control uses the predictive models to predict the inductor current, capacitor voltage and load current, so that the controlled variable fluctuates around its reference value. ${ }^{[15]}$ The switching time is the same as the prediction horizon $T_{s}$, during that time output only one voltage vector, if there are no additional constraints, the same voltage vector may be generated for several consecutive switching cycles. Therefore, the predictive control's switching frequency is varied.

In literatures by Mosa $\mathrm{M}$ et al., ${ }^{[13,14]}$ the working state of inductance current is analyzed in detail, and the predictive control algorithm is optimized by inductance current, which reduces the calculation of predictive control algorithm and achieves good control effect. However, the switching frequency is not considered in this paper, so it neglected that may cause larger inductance current and load current ripple. Based on those two literatures, in this paper, the working state of quasi-Z-source inverter is analyzed, and the problems caused by high switching frequency and low switching frequency are discussed in detail.

If the switching frequency is too low, there may cause the multiple switching states will be the same, and the controlled variable will deviate from the given value, which resulting in greater deviation. When a consecutive switching states are shoot-through vectors would cause a large inductor current ripple and large load current ripple (see Figure 5).

The inductor is charging in the shoot-through state, and discharging in the non-shoot-through state. According to the volt-second balance principle, the charging ripple of the inductor is equal to the discharge ripple.

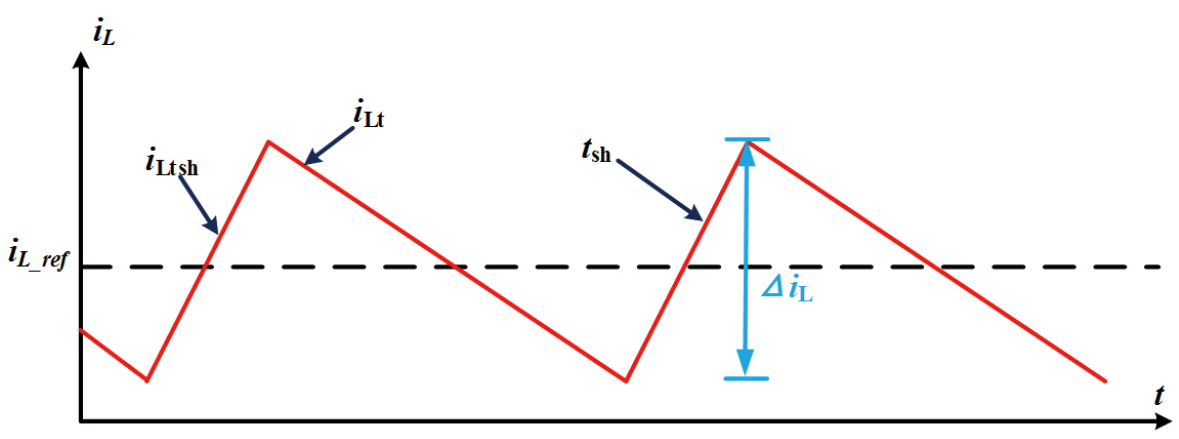

Figure 5. Inductor current ripple

When $t=T_{s}$, the charging current ripple of the inductor is $i_{L s h 1}$, and the discharge current ripple of the inductor is $i_{L N s h 1}$, which satisfies:

$$
i_{\mathrm{Lsh} 1}=i_{\mathrm{LNsh} 1}
$$

When $t=2 T_{s}$, the charging current ripple of the inductor is $i_{L s h}$, and the discharge current ripple of the inductor is $i_{L N s h}$, which satisfies:

$$
i_{\mathrm{Lsh}}=i_{\mathrm{LNsh}}
$$

Since the value of the inductor current is proportional to the charging or discharging time under the same inductance, it is:

$$
\Delta i_{\mathrm{L} 2}=2 \Delta i_{\mathrm{L} 1}
$$


As can be seen that when the prediction horizon is increased to double the inductor current ripple is also doubled, so the longer the prediction horizon, the charging and discharging inductor current ripple is greater.

\section{SHORT HORIZON MPC}

\subsection{The principle of switching frequency control}

In order to improve the switching frequency of the MPC, and overcome the problem that the big inductor current ripple and poor load current quality caused by low switching frequency. This paper proposed a short horizon predictive control algorithm, on the one hand, which by reducing the prediction horizon $T_{s}$ to improve the operating frequency of the switching device, the action time of the shoot-through vector and the non-shoot-through vector is greatly shortened, thereby improved the quality of the inverter output waveform; On the other hand, the high frequency band caused by the short horizon is limited. When the switching frequency exceeds the maximum switching frequency, the prediction state is selected in combination with the historical switching state to eliminate the high frequency band. Which not only improve the control effect of the predictive control algorithm but also the switching loss can be improved.

\subsection{Switching frequency control algorithm}

When the short horizon predictive control algorithm is adopted, the final applied switching action depends not only on the predicted optimal vector, but also on the historical state of the switching action. Firstly, the predictive control model is used to obtain the predicted values of all switch states at time $k+1$, and then the cost function is used to find the optimal vector of the switch action. Finally, the switch state of the switch action is selected in conjunction with the historical state of the switch action.

\subsubsection{Cost function}

In order to obtain the optimal switching action, the weight coefficients of the cost function need to be matched. The cost function of the predictive control algorithm is:

$$
\begin{aligned}
& G=\lambda \cdot y \\
& y=\left\|i_{\alpha}-i_{\alpha_{-} r}\right\|_{2}^{2}+\left\|i_{\beta}-i_{\beta_{-} r}\right\|_{2}^{2}+\left\|i_{L^{-}}-i_{L_{-} r}\right\|_{2}^{2}+\left\|V_{C}-V_{C_{-} r}\right\|_{2}^{2}
\end{aligned}
$$

Where $\lambda$ is a weight matrix, the larger the value of the weight coefficient, the greater the adjustment weight, and the greater the adjustment of the variable.

\subsubsection{Switching frequency control strategy}

If the switching action depends on the predicted value, the switching frequency of the inverter can be increased, but sometime the switching frequency will too high. In this paper, when the switching frequency is lower than the limit frequency, the switching action is obtained by the cost function. When the switching frequency is higher than the limit frequency the vector is selected by the fewest switching action of the switch to reduce the switching frequency.

The switching frequency adjustment measures are: the upper tubes of the three-phase inverter bridge are respectively selected as: $u_{a}, u_{b}, u_{c}$ and the lower tubes are $\bar{u}_{a}, \bar{u}_{b}, \bar{u}_{c}$ when the switch is turned on, the value is 1 , and when the switch is off, the value is 0 . Set a variable $n$ with an initial value of 0 . When the switch is switched, the value of $n$ is increased by 1 . The statistical function of the switch action is:

$$
f(x)=\sum\left\{n a, n_{\bar{a}}, n b, n_{\bar{b}}, n c, n_{\bar{c}}\right\}
$$

When the switching frequency is higher than the limit frequency, the switching state is determined by the optimal estimate, i.e.:

$$
G=G_{N}
$$

When the switching frequency is lower than the limit frequency, select the vector by the fewest switching action of the switch, i.e.:

$$
G=\min \left(G_{N-1}, G_{N}\right)
$$

Where $N$ is the statistical number of predictive control, $G$ is the cost function.

\section{Simulation AND EXPERIMENT}

In order to verify that the short horizon prediction control algorithm can significantly improve the control effect of inductor current and load current, the simulation system is built by Matlab/Simulink. Then the short horizon prediction control algorithm and the method used in the literature by Bakeer A et al. ${ }^{[15]}$ are simulated. The experimental program of two algorithms is written on the CCS development platform, and the two algorithms are experimentally verified on the quasi-Z source experimental platform.

\subsection{Simulation analysis}

The simulation parameters are: The system input voltage $V_{i n}$ $=50 \mathrm{~V}$, the parameters of the quasi- $\mathrm{Z}$ source network are $L_{1}=L_{2}=2 \mathrm{mH}, \mathrm{Cl}_{1}=C_{2}=500 \mu \mathrm{F}$, load resistance $R=$ $10 \Omega$, load inductance $L_{\text {load }}=8 \mathrm{mH}$. When $D=0.25$ and 
$m=0.7$, the average value of the inductor current is $4.76 \mathrm{~A}$, and the values of the bus voltage and the capacitor voltage are only related to the shoot-through-duty ratio $D$, so these two values remain unchanged. The bus voltage is $100 \mathrm{~V}$ and the capacitor voltage is $75 \mathrm{~V}$.

Figure 6 shows the simulation results of the two algorithm. When the quasi-Z-source working at the steady state, then changing the modulation degree $m$ from 0.5 to 0.7 . It can be seen that the controlled variables fluctuating around the reference value. Comparing the inductor simulation result,
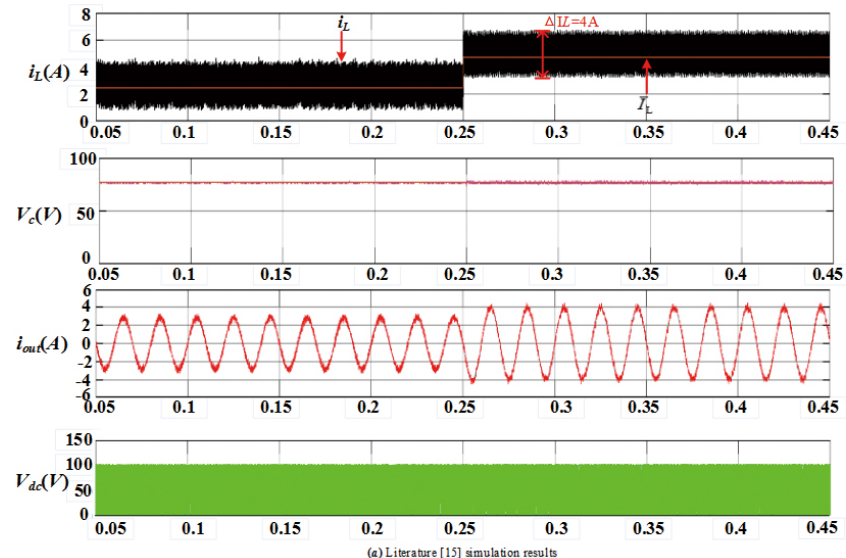

Figure 6. The overall tracking simulation results

It can be seen from the simulation results that the inductor current can be stably tracked near its references. However, comparing the two algorithms, it can be seen that the inductor current ripple is greatly reduced when the short horizon prediction control algorithm is used. It is verified that the longer the prediction horizon, the larger the ripple of the inductor current, this will cause the bus voltage to drop and the inverter output waveform to be distorted.

Figure 7 is a simulation result of the load current when the

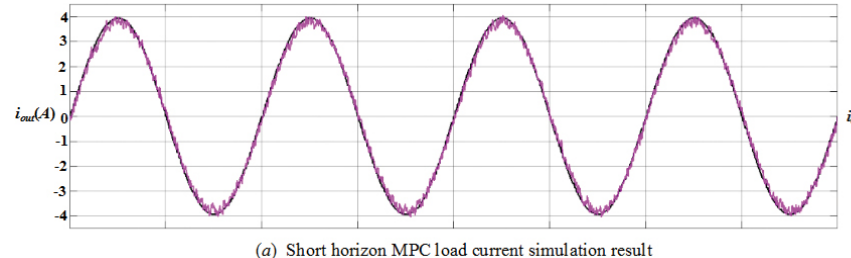

(a) Short horizon MPC load current simulation resul

Figure 7. Load current simulation result

\subsection{Experimental analysis}

To further verify the feasibility of the algorithm, using TI's DSP TMS320F28335 chip as the control core for data processing. During the experiment, the control effect of the it can be seen that both the two algorithm has good tracking effect, but the short horizon MPC's inductor current ripple significantly smaller. Figure 6(a) shows the simulation results of the inductor current, capacity voltage, load current and bus voltage of the literature by Bakeer $\mathrm{A}$ et al. ${ }^{[15]}$ It can be seen that the inductor current ripple is $2 \mathrm{~A}$. Figure $6(b)$ shows the simulation results of the inductor current, capacity voltage, load current and bus voltage of the short horizon prediction control algorithm. It can be seen that the inductor current ripple is $4 \mathrm{~A}$.
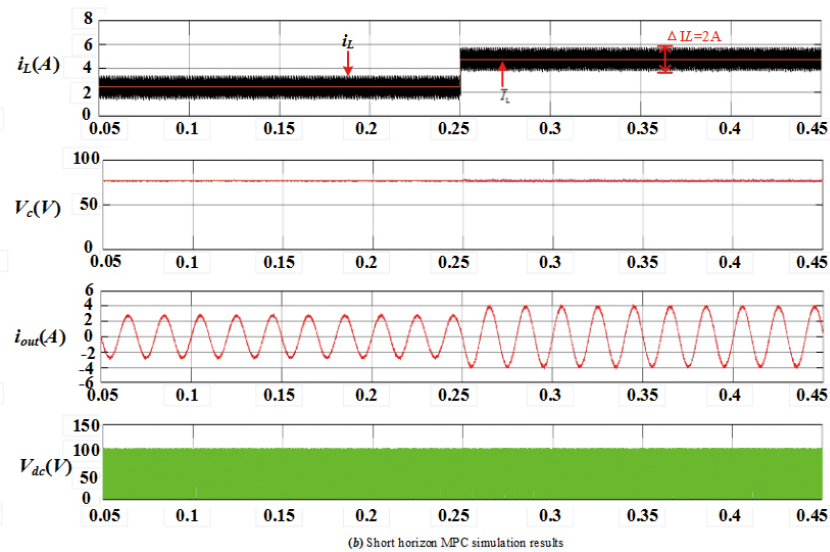

modulation degree is $m=0.7$ It can be seen that the load current can be tracked near its reference command under both conditions, and the peak value of the load current is 3.93A. Comparing Figure 7( $a$ ) and Figure 7(b), it can be seen that when the prediction horizon is smaller, the ripple of the load current is smaller, and the inverter has a better output characteristics, but the simulation experiments are performed under ideal conditions, the experimental results don't seem to be obvious.

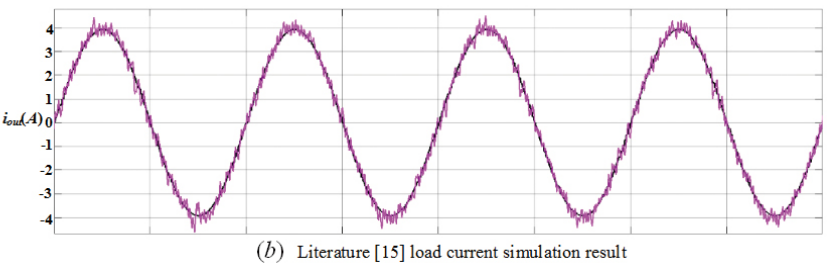

(b) Literature [15] load current simulation result inductor current, bus voltage and load current was observed with an oscilloscope. The experimental platform is shown in Figure 8. The experimental conditions and parameters are the same with the simulation. 


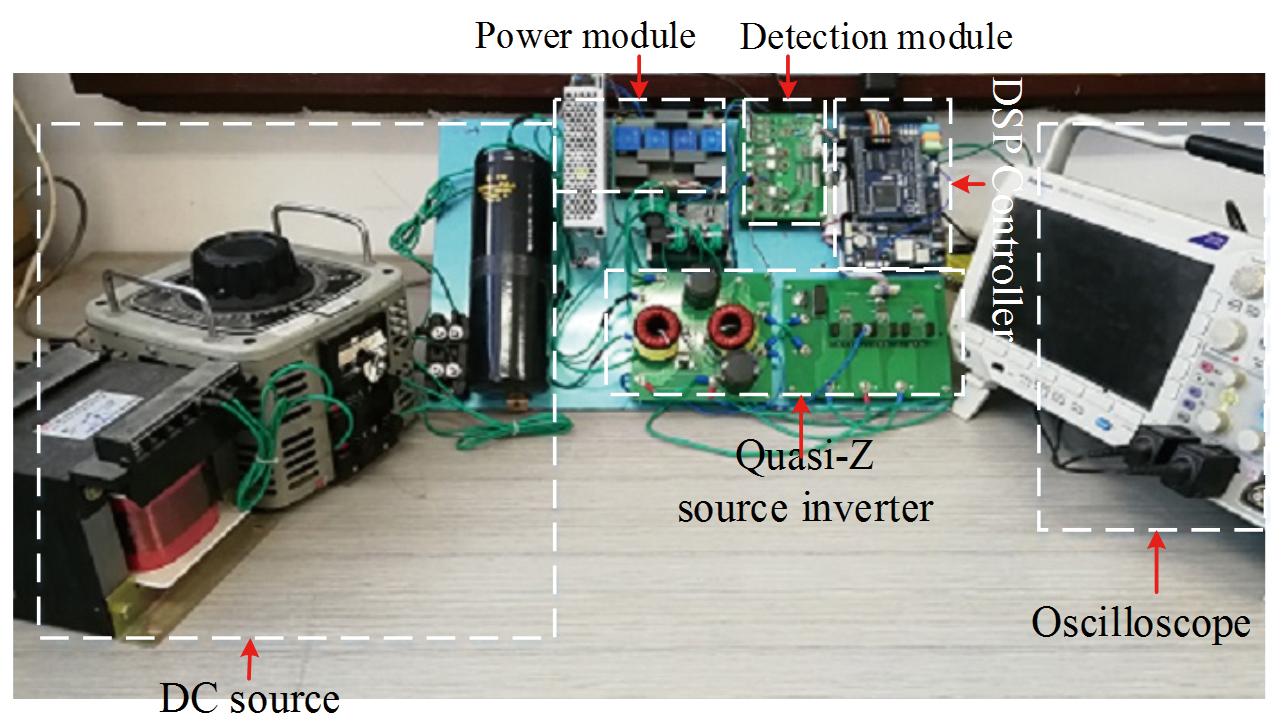

Figure 8. Experimental platform

Figure 9 shows the experiment results of the two algorithm. When the quasi-Z-source working at the steady state, then changing the modulation degree $m$ from 0.5 to 0.7 . It can be seen that the controlled variables fluctuating around the reference value, and the bus voltage does not fallen. Comparing Figure 9(a) and Figure 9(c), it can be seen that both the

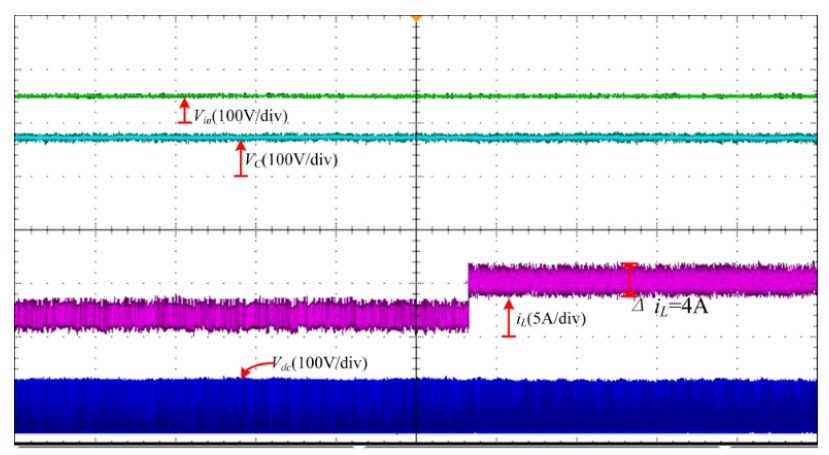

(a)

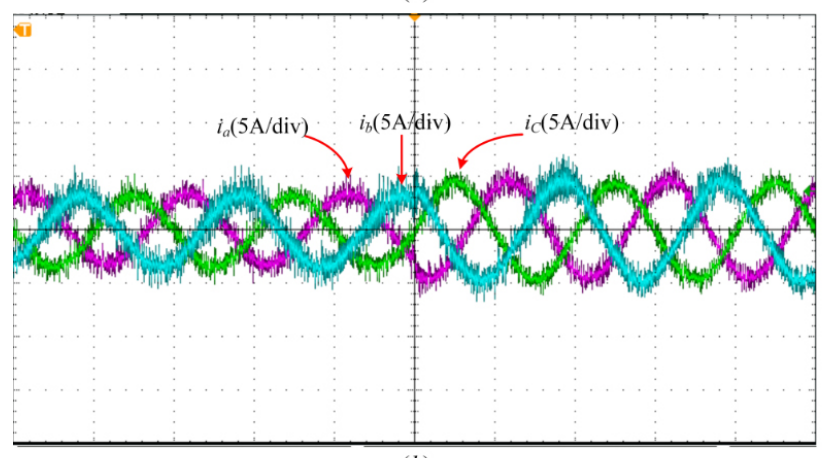

(b) two algorithm has good tracking effect, but the short horizon MPC's inductor current ripple significantly smaller. Comparing Figure 9(b) and Figure 9(d), it can be seen that when the $T_{s}$ is smaller, the waveform quality of the load current is better, which proves that the reduction of the prediction horizon has a significant improvement on the load current.

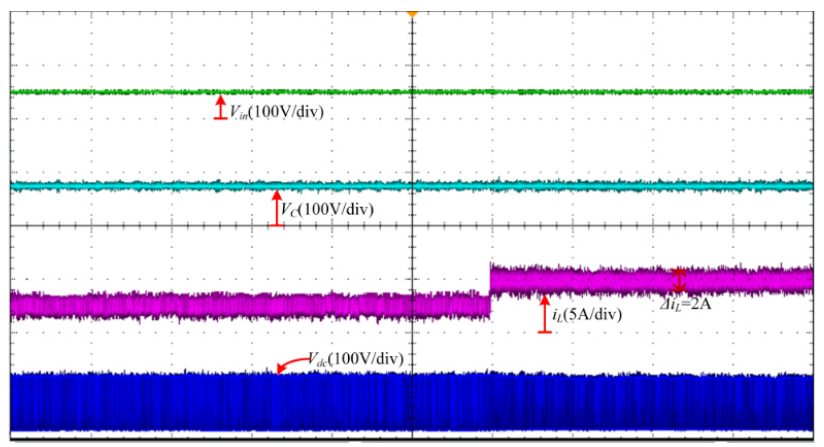

(c)

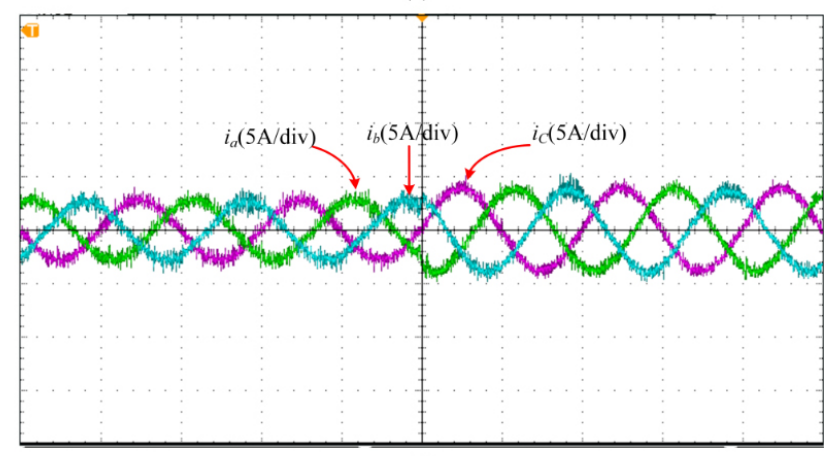

(d)

Figure 9. Experiment result. (a) The overall tracking of experimental results of literature by Bakeer A, et al. ${ }^{[15]}(b)$ The load current experiment result of literature by Bakeer A, et al. ${ }^{[15]}(c)$ The overall tracking of experimental results of short horizon MPC. $(d)$ The load current experiment result of short horizon MPC. 
It can be seen from the experiment that the proposed method has better control effect, and which verifies the correctness and feasibility of the theory.

\section{Conclusion}

In order to solve the problem that the inductor current ripple wave is large due to the unfixed switching frequency, and the inverter output waveform quality is low, this paper proposed a short horizon predictive control algorithm. The relationship between the predicted horizon and the switching frequency is studied in detail, and the effects of the inductor current and output characteristics of the quasi-Z-source inverter when the switching frequency is too low and too high are analyzed. The quasi-Z source inverter is adjusted by taking appropriate prediction horizon, and the operating frequency of the inverter is improved by this method. Finally, the simulation and experimental results shows that the method can effectively reduce the ripple of the inductor current and improve the output waveform quality of the inverter.

\section{REFERENCES}

[1] Peng FZ. Z-source inverter. IEEE Transactions on Industry Applications. 2003; 39(2): 504-510. https ://doi.org/10.1109/TIA . 2003.808920

[2] Sun D, Ge B, Zhang H, et al. An energy stored quasi-Z source cascaded multilevel inverter based photovoltaic power generation system. Applied Power Electronics Conference and Exposition. IEEE. 2014: 1747-1751.

[3] Ding X. Single-Stage Control of MPPT and Grid-Connected on ZSource Inverter PV System. Transactions of China Electrotechnical Society. 2010; 25(4): 122-126.

[4] Arun SPS, Suresh KV, Vinayaka KU. Hybrid wind-solar systems using CUK-SEPIC fused converter with quasi-Z-source inverter. Power, Communication and Information Technology Conference. IEEE. 2016: 856-861.

[5] Geyer T, Papafotiou G, Morari M. Model Predictive Control in Power Electronics: A Hybrid Systems Approach. Decision and Control, 2005 and 2005 European Control Conference. Cdc-Ecc '05. IEEE Conference on. IEEE, 2005: 5606-5611.

[6] Yu-Geng XI, De-Wei LI, Shu LIN. Model Predictive Control — Status and Challenges. Acta Automatica Sinica. 2013; 39(3): 222-236. https://doi.org/10.1016/S1874-1029(13)60024-5

[7] Rodriguez J, Kazmierkowski MP, Espinoza JR, et al. State of the Art of Finite Control Set Model Predictive Control in Power Electronics. IEEE Transactions on Industrial Informatics. 2013; 9(2): 1003-1016. https://doi.org/10.1109/TII.2012.2221469

[8] Vazquez S, Leon JI, Franquelo LG, et al. Model Predictive Control: A Review of Its Applications in Power Electronics. Industrial Electronics Magazine IEEE. 2014; 8(1): 16-31. https://doi .org/10 $.1109 /$ MIE. 2013. 2290138
[9] Ayad A, Kennel R. Direct model predictive control of quasi-Z-source inverter compared with the traditional PI-based PWM control. European Conference on Power Electronics and Applications. IEEE; 2015.

[10] Liu J, Jiang S, Cao D, et al. A Digital Current Control of QuasiZ-Source Inverter With Battery. IEEE Transactions on Industrial Informatics. 2013; 9(2): 928-937.

[11] Abdelhakim A, Davari P, Blaabjerg F, et al. Switching Loss Reduction in the Three-Phase Quasi-Z-Source Inverters Utilizing Modified Space Vector Modulation Strategies. IEEE Transactions on Power Electronics. 2017; PP(99): 1-1.

[12] Lei Q, Cao D, Peng FZ. Novel SVPWM switching pattern for high efficiency $15 \mathrm{KW}$ current-fed quasi-Z-source inverter in HEV motor drive application. Applied Power Electronics Conference and Exposition. IEEE. 2012: 2407-2420.

[13] Mosa M, Dousoky GM, Abu-Rub H. A novel FPGA implementation of a model predictive controller for SiC-based Quasi-Z-Source inverters. Applied Power Electronics Conference and Exposition. IEEE. 2014: 1293-1298.

[14] Mosa M, Balog R, Abu-Rub H. High Performance Predictive Control of Quasi Impedance Source Inverter. IEEE Transactions on Power Electronics. 2016; PP(99): 1-1.

[15] Bakeer A, Ismeil MA, Orabi M. A Powerful Finite Control SetModel Predictive Control Algorithm for Quasi Z-Source Inverter. IEEE Transactions on Industrial Informatics. 2016; 12(4): 13711379. https://doi.org/10.1109/TII.2016.2569527

[16] Ayad A, Karamanakos P, Kennel R. Direct Model Predictive Current Control Strategy of Quasi-Z-Source Inverters. IEEE Transactions on Power Electronics. 2017; 32(7): 5786-5801. https: //doi.org/10.1109/TPEL.2016.2610459 